\title{
Estabelecimento de metodologia para alimentação de Aedes aegypti (Diptera-Culicidae) em camundongos swiss e avaliação da toxicidade e do efeito residual do óleo essencial de Tagetes minuta L (Asteraceae) em populações de Aedes aegypti
}

\author{
Establishment of the feeding methodology of Aedes aegypti (Diptera-Culicidae) in \\ Swiss mice and evaluation of the toxicity and residual effect of essential oil from \\ Tagetes minuta L (Asteraceae), in populations of Aedes aegypti
}

\author{
Waldemir Pereira Lima ${ }^{1}$, Francisco Chiaravalloti Neto ${ }^{1,2}$, Maria de Lourdes da Graça Macoris ${ }^{3}$, \\ Débora Aparecida Pires de Campos Zuccari ${ }^{1}$ e Margareth Regina Dibo ${ }^{1,2}$
}

\begin{abstract}
RESUMO
Objetivou-se desenvolver um procedimento de alimentação de fêmeas de Aedes aegypti que não cause estresse em camundongo swiss e avaliar a toxicidade e o efeito residual do óleo essencial de Tagetes minuta L (Asteraceae) em populações de Aedes aegypti. Camundongos anestesiados: um observado tempo de sedação e outro colocado em gaiola para alimentação de fêmeas. Óleo essencial, diluído em acetona, foi utilizado em bioensaios para avaliação das concentrações letais em larvas de Bauru, SP e São José do Rio Preto, SP, respectivamente, sensíveis e resistentes ao temephos. Os dados obtidos foram comparados com a cepa Rockefeller-EUA. 0 procedimento com camundongos foi aprovado. Não houve diferença

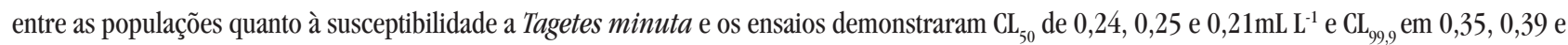
$0,42 \mathrm{~mL} \mathrm{~L}^{-1}$, respectivamente, para Rockfeller, Bauru e São José do Rio Preto. Não foi observado efeito residual da solução.
\end{abstract}

Palavras-chaves: Metodologia em alimentação. Aedes aegypti. Tagetes minuta. Óleo essencial. Camundongos swiss.

\begin{abstract}
The objectives here were to develop a procedure for feeding females of Aedes aegypti that does not cause stress in Swiss mice and to evaluate the toxicity and residual effect of essential oil from Tagetes minuta L. (Asteraceae) in Aedes aegypti populations. Two mice were anesthetized: one was used to observe the duration of sedation and the other was placed in a cage to feed the female mosquitoes. Essential oil was diluted in acetone and used in bioassays to assess the lethal concentrations in larvae from the Cities of Bauru (SP) and São José do Rio Preto (SP) that were sensitive and resistant to temephos, respectively. The data obtained were compared with the American Rockefeller strain. The procedure with mice was approved. There was no difference between the populations regarding susceptibility to Tagetes minuta, and the assays showed $\mathrm{LC}_{50}$ of $0.24,0.25 \mathrm{and} 0.21 \mathrm{ml} / \mathrm{l}$ and $\mathrm{LC}_{99.9}$ of $0.35,0.39$ and $0.42 \mathrm{ml} / \mathrm{l}$, for Rockefeller, Bauru and São José do Rio Preto, respectively. The solution did not show any residual effect.
\end{abstract}

Key-words: Food methodology. Aedes aegypti. Tagetes minuta. Essential oil. Swiss mice.

A dengue, doença considerada problema de saúde pública nos países tropicais subdesenvolvidos e em desenvolvimento, ameaça milhares de pessoas principalmente no Brasil. 0 mosquito Aedes aegypti (Diptera-Culicidae), procedente da África, trazido para a América durante o processo de colonização é o vetor

1. Curso de Ciências da Saúde, Faculdade de Medicina de São José do Rio Preto, São José do Rio Preto, SP. 2. Superintendência de Controle de Endemia, Serviço Regional 08, São José do Rio Preto, SP. 3. Superintendência de Controle de Endemias, Serviço Regional 11, São José do Rio Preto, SP.

Endereço para correspondência: Dra. Margareth Regina Dibo. Laboratório de Vetores/FAMERP. Av. Brigadeiro Faria Lima 5416, V. São Pedro, 15090-000 São José do Rio Preto, SP.

Tel: 5517 3201-5901; 3201-5900.

e-mail: medibo@famerp.br

Recebido para publicação em 19/06/2009

Aceito em 19/10/2009 responsável pela transmissão do vírus da família Flaviviridae, gênero Flavivirus, causador da doença ${ }^{5}{ }^{18}$.

Desde o século IX, várias substâncias foram utilizadas como inseticida na tentativa de se eliminar este vetor: arsênico, mercúrio, enxofre, organoclorados, organofosforados. 0 principal problema que estes agentes apresentam é a alta toxicidade e alguns deles se acumulam na cadeia alimentar?

Os piretróides, substâncias extraídas de vegetais, os quais surgiram na década de 70, possuem baixa toxicidade a mamíferos, sendo o inseticida de escolha pelos órgãos de saúde pública para combate aos vetores de doenças. Porém, com o uso indiscriminado destes agentes, muitos culicídeos passaram a desenvolver resistência frente a estes compostos, dentre eles o Aedes aegypti ${ }^{2810}$.

A imensa biodiversidade da flora brasileira e o potencial inseticida de diversas espécies ainda inexploradas surgem 
como uma fonte de novos agentes químicos para o controle de culicídeos, principalmente o Aedes aegypti $i^{45}$

Diversas plantas brasileiras têm sido avaliadas quanto à atividade larvicida contra o Aedes aegypti. Dentre elas destacam-se: Cybistax antisyphilitica, Andiroba, Cynbopogon citratus, Lippia sidoides, Ocimum americanum, Ocimum gratissimum, Melia azedarach, Azadirachta indica, Eupatorium betonicaeforme, Tegetes minuta, Senecio brasiliensis, Tagetes patula, Tagetes erecta, Vernonia ammophila ${ }^{415}$

Para a realização de testes com larvicidas, utiliza-se um número elevado de exemplares (em torno de 800 por teste) os quais devem ter sido criados em condições semelhantes de nutrição e desenvolvimento fisiológico. Para tal padronização é necessária a criação desta espécie em laboratório. Geralmente os testes são realizados com a primeira geração obtida em laboratório (F1) por ser a mais próxima da população natural. Entretanto, não se encontram artigos científicos com procedimentos aprovados por Comitês de Ética em Experimentação Animal referentes à utilização de camundongos como fonte de repasto sanguíneo para fêmeas deste Culicídeo, o que é necessário para postura de ovos e criação em laboratório. Assim, o primeiro objetivo deste estudo é desenvolver um procedimento de alimentação de fêmeas de Aedes aegypti que não cause estresse ou sofrimento para o camundongo e que esteja em acordo com as normas estabelecidas pelos Comitês de Ética em Experimentação Animal. 0 segundo objetivo é avaliar a toxicidade e o efeito residual do óleo essencial de Tagetes minuta L (Asteraceae) em populações de Aedes aegypti com diferentes perfis de susceptibilidade ao organophosphorado temephos, larvicida intensamente utilizado no Programa de Controle de Dengue, desde a década de 80.

\section{MATERIAL E MÉTODOS}

0 procedimento de contenção de camundongos por um período determinado para alimentação de mosquitos, anteriormente utilizado em insetários, provoca um efeito estressante no comportamento dos indivíduos, reduzindo sua movimentaçã $0^{9}$. Como alternativa a este procedimento, buscou-se o desenvolvimento de metodologia de alimentação sanguínea das fêmeas de Aedes aegypti que não causasse estresse a camundongos swiss e que estivesse de acordo com os princípios éticos na experimentação animal. Para isso, dois experimentos foram realizados, sob supervisão de um dos autores que é Médico Veterinário (DAPCZ). Em ambos os experimentos, foram administrados por via intramuscular, através de uma seringa hipodérmica $0,05 \mathrm{~mL}$ de ketamina e $0,05 \mathrm{~mL}$ de xilasina, respectivamente, em volume total de $0,1 \mathrm{~mL}$ de anestésicos em camundongo swiss. A utilização de anestésicos para diminuir o desconforto e a ansiedade na total impossibilidade dos animais em responder ao estímulo, tem apoio nos princípios éticos na experimentação animal, pois a sensibilidade do animal é similar à humana no que se refere a dor, memória, angústia, instinto de sobrevivência. Desta maneira, deve ser garantida, aos animais utilizados em experimentos, sedação, analgesia ou anestesia, quando se configurar a possível ocorrência de dor ou angústia, rejeitando, sob qualquer argumento ou justificativa, o uso de agentes químicos e/ou físicos paralisantes e não anestésicos.

No primeiro experimento, um animal foi deixado em repouso em recipiente próprio, forrado de serragem e observado o tempo de sedação. No segundo procedimento, um animal sedado foi exposto a 40 fêmeas do mosquito Aedes aegypti em gaiola apropriada e observado. Uma vez estabelecidos os parâmetros de criação dos mosquitos, isto é, número de mosquitos fêmea por gaiola e duração e frequência de alimentação no camundongo, esta metodologia foi utilizada para obtenção de ovos de Aedes aegypti de São José do Rio Preto, a serem utilizados nos testes com Tagetes minuta L. Por este experimento, larvas de Aedes aegypti foram coletadas durante visitas às residências pelos agentes municipais do Programa de Controle da Dengue, em diferentes bairros de São José do Rio Preto, as quais foram encaminhadas ao laboratório e alimentadas com ração para peixe até atingir a fase adulta. Fêmeas e machos foram colocados em uma gaiola de criação de mosquitos. Para estes, foram oferecidas solução açucarada a 10\% alternada com a exposição de camundongos swiss durante três dias da semana, visando a hematofagia pelas fêmeas e oviposição. Os ovos obtidos foram colocados para secar a temperatura ambiente, em seguida contados e armazenados. Os ovos de Aedes aegypti de Bauru e cepa Rockfeller (originária dos Estados Unidos e cedida pelo Centers of Disease Control de Porto Rico), também necessários para realização dos testes, foram fornecidos pelo Laboratório da Superintendência de Controle de Endemias (SUCEN) de Marília.

Os ovos de cada população foram colocados em vasilhas contendo água e fermento e as larvas foram alimentadas com ração para peixe, até atingir o terceiro estágio de desenvolvimento. Para estabelecimento de curva de dose-resposta, foi utilizada metodologia da Organização Mundial da Saúde para bioensaios com larvas, isto é, ensaio com dose diagnóstica, que é a exposição de larvas ao dobro da CL 99 da cepa susceptível de referência e ensaio de estimativa de razão de resistência para ambos os ensaios e a cepa referência foi Rockefeller. 0 óleo essencial de Tagetes minuta $\mathrm{L}$ foi adquirido junto à empresa SAT Group (Índia) que o extrai através da metodologia de arraste a vapor conforme descrito por Alencar cols ${ }^{1}$, utilizando-se um aparelho de Clevenger; o hidrolato é recolhido e as fases aquosa e orgânica são separadas por centrifugação, em centrífuga de cruzeta horizontal a $965 \mathrm{~g} \mathrm{a}$ $25^{\circ} \mathrm{C}$ por 5 minutos, sendo o material coletado após a floração. Este óleo foi diluído e testado nas concentrações de $0,2 \mathrm{~mL} \mathrm{~L}^{-1}$; $0,225 \mathrm{~mL} \mathrm{~L}^{-1} ; 0,25 \mathrm{~mL} \mathrm{~L}^{-1} ; 0,275 \mathrm{~mL} \mathrm{~L}^{-1}$ e $0,3 \mathrm{~mL} \mathrm{~L}^{-1}$ partindo-se de uma diluição inicial de $200 \mathrm{~mL} \mathrm{~L}^{-1}$ em Acetona.

A partir da solução inicial, foram preparadas para cada diluição, quatro recipientes com volume final de $150 \mathrm{~mL}$ cada um, uma vez que todos os testes foram realizados em quadriplicata. Os recipientes testemunha foram preparados também em quadriplitaca contendo $0,3 \mathrm{~mL}$ de Acetona, em volume final de $150 \mathrm{~mL} \mathrm{~L}^{-1}$. Todos os testes foram realizados em três repetições, por três dias consecutivos, sendo que cada bateria de testes foi realizada no mesmo dia para cada população do inseto.

Em cada um dos recipientes teste e testemunha, foram distribuídas 25 larvas do mosquito das diferentes procedências 
onde foi observada a porcentagem de mortalidade após período de contato de 24 horas. A porcentagem de mortalidade foi calculada totalizando-se o número de larvas expostas e mortas por dose em cada teste realizado. Esta foi corrigida pela fórmula de Abbott, caso a mortalidade no controle fosse entre 05 e $20 \%{ }^{17}$ :

$$
\frac{\% \text { mortalidade (teste) }-\% \text { mortalidade (controle) x } 100}{100-\% \text { mortalidade (controle) }}
$$

A partir dos dados de mortalidade por dose foram estimadas, por análise de Probit, as $\mathrm{CL}_{50}, \mathrm{CL}_{95}, \mathrm{CL}_{99}$ e $\mathrm{CL}_{99,9}$. A partir da $\mathrm{CL}_{99}$ foram realizados testes para verificação do período residual do óleo, utilizando-se três concentrações $\left(\mathrm{CL}_{99}\right.$, o dobro e o triplo), dois controles (ambos em quadriplicata) e três repetições, as quais foram expostas pelo período de uma semana, em laboratório, e posteriormente adicionadas as larvas de terceiro estágio em cada recipiente e observada a mortalidade após 24 horas.

\section{RESULTADOS}

No primeiro experimento, para avaliação do procedimento de alimentação das fêmeas de Aedes aegypti, o camundongo swiss permaneceu totalmente imóvel por uma hora e sedado por igual período, ou seja, duas horas após o procedimento anestésico, tempo suficiente para a alimentação dos mosquitos, que não ultrapassa uma hora. Não houve qualquer indício de que o animal passou por dor ou estresse.

No segundo experimento com camundongo, cerca de cinco minutos após a administração da mesma quantidade de anestésicos, o animal já se encontrava sedado e foi exposto às fêmeas de Aedes aegypti, para realizarem a hematofagia, sendo que o animal permaneceu imóvel por uma hora. Após este período, o camundongo foi retirado da gaiola e encaminhado ao Biotério da Faculdade de Medicina de São José do Rio Preto. Cerca de três horas após a administração do anestésico, o animal passou a apresentar movimentos, quando o período de sedação do anestésico começou a cessar. Pode-se notar que o tempo de exposição foi suficiente para alimentação das fêmeas de Aedes aegypti, que não ultrapassa uma hora. Estas informações foram apresentadas ao Comitê de Ética em Experimentação Animal da Faculdade de Medicina de São José do Rio Preto, o qual aprovou o procedimento adotado através do Processo ํㅜ 5741/07.

Os resultados da avaliação da ação do óleo essencial de Tagetes minuta L contra larvas em $3^{\circ}$ estágio de Rockfeller (EUA), Bauru (SP) e São José do Rio Preto (SP) são apresentados na Tabela 1. As Concentrações letais do óleo essencial de Tagetes minuta L para larvas de Aedes aegypti estão demonstrados na Tabela 2. Os testes para avaliação do período residual do óleo essencial de Tagetes minuta $\mathrm{L}$ realizados com o dobro e o triplo da $\mathrm{CL}_{99}$ demonstraram mortalidade zero, após uma semana de contato, bem como em todos os controles.

\section{TABELA 1}

Percentual médio de mortalidade e Desvio Padrão (DP) para diferentes concentrações do óleo essencial de Tagetes minuta L e controle, contra 100 larvas ( $3^{\circ}$ estágio) de Aedes aegypti procedentes de Rockfeller (EUA), Bauru (SP) e São José do Rio Preto

\begin{tabular}{|c|c|c|c|c|}
\hline & & Rockefeller & Bauru & São José Rio Preto \\
\hline Produto & $\mathrm{mL} \mathrm{L}^{-1}$ & $\% \pm \mathrm{DP}$ & $\% \pm \mathrm{DP}$ & $\% \pm \mathrm{DP}$ \\
\hline \multirow[t]{5}{*}{ Tagetes minuta } & 0,200 & $11,0 \pm 1,7$ & $45,3 \pm 25,5$ & $32,6 \pm 17,0$ \\
\hline & 0,225 & $27,0 \pm 1,0$ & $43,0 \pm 25,2$ & $57,3 \pm 4,00$ \\
\hline & 0,250 & $39,3 \pm 1,1$ & $62,0 \pm 26,0$ & $67,0 \pm 5,20$ \\
\hline & 0,275 & $85,3 \pm 1,1$ & $73,6 \pm 5,7$ & $69,0 \pm 8,70$ \\
\hline & 0,300 & $99,0 \pm 1,0$ & $93,6 \pm 1,5$ & $93,0 \pm 4,30$ \\
\hline Acetona(controle) & 0,300 & 0 & 0 & 0 \\
\hline
\end{tabular}
(SP), após 24 horas de contato ${ }^{a}$.

año houve necessidade de correção da mortalidade.

TABELA 2

Concentrações letais do óleo essencial de Tagetes minuta L, contra 100 larvas ( $3^{\circ}$ estágio) de Aedes aegypti, procedentes de Rockfeller (EUA), Bauru (SP) e São José do Rio Preto (SP), após 24 horas de contato.

\begin{tabular}{lcccc}
\hline \multirow{2}{*}{ Procedência das larvas } & $\begin{array}{c}\mathrm{CL}_{90} \\
\mathrm{~mL} \mathrm{~L}^{-1}\end{array}$ & $\begin{array}{c}\mathrm{CL}_{95} \\
\mathrm{~mL} \mathrm{~L}^{-1}\end{array}$ & $\begin{array}{c}\mathrm{CL}_{99} \\
\mathrm{~mL} \mathrm{~L}^{-1}\end{array}$ & $\begin{array}{c}\mathrm{CL}_{99} \\
\mathrm{~mL} \mathrm{~L}^{-1}\end{array}$ \\
\hline Rockefeller & 0,2400 & 0,2900 & 0,3200 & 0,3500 \\
& $(0,22-0,26)$ & $(0,27-0,36)$ & $(0,29-0,43)$ & $(0,34-0,38)$ \\
\hline Bauru & 0,2500 & 0,3200 & 0,3500 & 0,3900 \\
& $(0,23-0,26)$ & $(0,29-0,39)$ & $(0,32-0,47)$ & $(0,37-0,43)$ \\
\hline São José do Rio Preto & 0,2100 & 0,3100 & 0,3600 & 0,4200 \\
& $(0,21-0,22)$ & $(0,3-0,33)$ & $(0,34-0,38)$ & $(0,39-0,46)$ \\
\hline
\end{tabular}

\section{DISCUSSÃO}

Durante a elaboração do projeto de pesquisa observou-se que procedimentos com camundongos que sejam aprovados por Comitês de Ética em Experimentação Animal não são encontrados em bibliografia nacional, muito embora sejam exigidos para submissão de projetos. Estes procedimentos visam elaborar e normatizar protocolos de utilização destes animais de laboratório, para que eles não sejam submetidos a situações de estresse e dor. 0 procedimento desenvolvido no presente trabalho é um protocolo aprovado pelo Comitê de Ética em experimentação Animal da Faculdade de Medicina de São José do Rio Preto, está de acordo com as normas destes Comitês e pode ser utilizado por outros pesquisadores que necessitem utilizar camundongos swiss.

0 uso de temephos no Brasil teve início na década de 80 e atualmente há registro de desenvolvimento de resistência a este produto em várias regiões do país. No Estado de São Paulo, há diferentes perfis de susceptibilidade a este produto havendo populações ainda sensíveis (Bauru) e outras já resistentes (São José do Rio Preto). Há, portanto, necessidade de manejo da resistência ao larvicida organofosforado. Além da recomendação de restrição do uso de produto químico, há necessidade de manejo com substituição de produtos.

Embora haja no mercado disponibilidade de outros grupos de larvicidas, como os inibidores de crescimento, por exemplo, é importante buscar alternativas mais naturais para o controle. Assim, estudos futuros devem ser desenvolvidos sobre outros produtos que possam atuar como forma alternativa no combate ao 
vetor. Extratos de plantas têm sido avaliados como uma alternativa ao controle químico por apresentarem efeito larvicida tendo como vantagem não serem tóxicos ao ambiente, como o óleo essencial de Tagetes minuta $\mathrm{L}$.

Maradufu cols ${ }^{11}$, utilizando concentração inferior do óleo essencial de Tagetes minuta L (10ppm) em 24 horas de contato, obtiveram menor mortalidade $(69 \% \pm 26)$ do que as obtidas neste trabalho em larvas de $3^{\circ}$ estágio de Aedes aegypti provenientes de Rockfeller (EUA), Bauru (SP) e São José do Rio Preto (SP). Entretanto, quando o tempo de contato foi aumentado para 48 horas, Maradufu cols ${ }^{11}$ obtiveram mortalidade de larvas próximas a $100 \%$.

Neste trabalho, as $\mathrm{CL}_{50} \mathrm{e} \mathrm{CL}_{90}$ para larvas de $3^{\circ}$ estágio de Aedes aegypti provenientes de Rockfeller (EUA), Bauru (SP) e São José do Rio Preto (SP) foram inferiores aos valores obtidos por Furtado cols ${ }^{5}$ utilizando óleo essencial de Tagetes minuta L contra as larvas de $3^{\circ}$ estágio das regiões de Caucaia e Quixeramobim-CE, onde ocorreram respectivamente $\mathrm{CL}_{50} \mathrm{eCL}_{90}$ de 72,85 e 104,17mg/L. A explicação das diferenças encontradas nos resultados obtidos no presente trabalho em relação aqueles obtidos por Maradufu cols $^{11}$ e Furtado cols ${ }^{5}$, que utilizaram extrato da mesma espécie de planta, podem ser observadas em trabalhos realizados por Vitti cols ${ }^{16}$ e Tavares cols ${ }^{15}$, pois segundo estes autores são vários os fatores que exercerem influência na composição química dos óleos essenciais: a variabilidade genética, a idade das folhas, as condições ambientais, o tipo de manejo florestal, os processos de extração e de análise do óleo, assim como o ambiente no qual o vegetal se desenvolve. A temperatura, a umidade relativa, a duração da exposição ao sol e o regime de ventos exercem uma influência direta, sobretudo nas estruturas histológicas das espécies de estocagem de óleo na superfície da folha.

0 encontro de mortalidade nula das larvas de Aedes aegypti, após uma semana de contato com o óleo essencial de Tagetes minuta L, não foi concordante com outros estudos. Green $\operatorname{cols}^{7}$ demonstraram que a propriedade larvicida do óleo na concentração de 10ppm disperso em água persistiu no mínimo por 9 dias. Porém, Maradufu cols ${ }^{11}$ obtiveram estabilidade do óleo por um período mais curto, ou seja, 72 horas.

Em todos os testes realizados, a avaliação da ação do óleo essencial foi por contato, podendo-se supor que o óleo é capaz de transpor estruturas da larva, desempenhando ação inseticida letal mesmo em pequenas concentrações, mecanismo sugerido por Perich cols ${ }^{12}$, no qual os tiofenos denominados de 5-(but-3-ene1-inil)-2,2'-bitiofeno, 5-(but-3-ene-1-inil)-5'-metil-2,2'-bitiofeno, 2,2‘, ',2-tertiofeno e 5-metil-2,2',5',2-tertiofeno, isolados da fração hidrogenada, obtida do extrato das flores, promoveram de 20-30 vezes mais toxicidade que outras partes do vegetal contra formas adultas de Aedes aegypti. Contudo, Maradufu cols ${ }^{11}$ demonstraram que a ação larvicida ocorre por ação do componente 5-(E)-ocimenona.

Os resultados indicam que o óleo essencial de Tagetes minuta L é potencialmente útil no controle deAedes aegypti. Os valores de concentrações letais das larvas Rockefeller comparado com as de campo são muito semelhantes, o que sugere que a resistência ao temephos não interfere na ação da Tagetes minuta L e demonstra que o referido óleo pode ser um larvicida alternativo contra larvas resistentes ao temephos. Entretanto, outros estudos devem ser realizados na tentativa de isolar a fração larvicida do óleo para incorporar componentes visando manter maior estabilidade, aumentando assim o efeito residual do produto.

\section{AGRADECIMENTOS}

Para Aline M.S. Pagliotto, Beatriz A.C. Belini, Daniela R. Benetti, Nathália Zini, Neuza F.A. Santana e Perpétua M.M. Sereno.

\section{REFERÊNCIAS}

1. Alencar JW, Craveiro AA, Matos FJA. Kovats indices as a presentation routine in mass espectro searches of voilaties. Journal of Nature Proceduce 47:890892,1984 .

2. Beserra EB, Ferdandes CRM, Queiroga MFC, Castro FPJ. Resistance of Aedes aegypti (L.) (Diptera: Culicidae) populations to organophosphates temephos in the Paraíba State, Brazil. Neotropical Entomology 36:303-307, 2007.

3. Cavalcanti ESB, Morais SM, Lima MA, Santana EWP. Larvicidal activity of essential oils from Brazilian plants against Aedes aegypt $i \mathrm{~L}$. Memórias do Instituto Oswaldo Cruz 99:541-544, 2004.

4. Fantinatti ECS, Duque JEL, Silva AM, Navarro-Silva MA. Abundância e Agregação de Ovos de Aedes aegypti $\mathrm{L}$ e Aedes albopictus (Skuse) (Diptera: Culicidae) no Norte e Noroeste do Paraná. Neotropical Entomology 36:960-965, 2007.

5. Furtado RF, Lima MGA, Neto MA, Bezerra JNS, Silva MGV. Larvicidal activity of essential oils against Aedes aegypti L (Diptera: Culicidae). Neotropical Entomology 34:843-847, 2005.

6. Gilman DA, Rall TW, Nies AS, Taylor RP. The Pharmacological basis of therapeutics. Editora MacGraww-Hill, Rio de Janeiro, 2003.

7. Green MM, Singer JM, Sutherland DJ, Hibben CR. Larvicidal activity of Tagetes minuta (marigold) toward Aedes aegypti. Journal of American Mosquitoes Control Association 7:282-286, 1991.

8. Lima EP, Oliveira Filho AMO, Oliveira Lima JW, Ramos Júnior ANR, Cavalcanti LPG, Pontes RJS. Resistência do Aedes aegypti ao temefós em municípios do estado do Ceará. Revista da Sociedade Brasileira de Medicina Tropical 39:259-263, 2006.

9. Lopes HC. Efeito de um Complexo Homeopático no Desempenho e no Comportamento de Camundongos sob Estresse Agudo. Dissertação de Mestrado. Universidade Federal de Mato Grosso do Sul, Faculdade de Medicina Veterinária e Zootecnia, Campo Grande, 2008.

10. Macoris MLG, Andrighetti MTM, Takaku L, Glasser CM, Garbeloto VC, Bracco JE. Resistance of Aedes aegypti from the state of São Paulo, Brazil to organophosphates insecticides. Memórias do Instituto Oswaldo Cruz 98:703-708, 2003.

11. Maradufu AR, Lubeya DF. Isolation of (5E) Ocimenone, a mosquito larvicide from Tagetes minuta. Lloydia 41:181-183, 1998.

12. Perich MJ, Wells C, Bersch W, Tredway KE. Isolation of the insecticidal components of Tagetes minuta (Compositae) against mosquito larvae and adults. Journal of the American Mosquito Control Association 11:307-310, 1995.

13. Sargent SR. Inseticidas Naturais, bioinseticidas e feromônios: solução para a Dengue? Sociedade Brasileira de Parasitologia 57:61-68, 2007.

14. Shaalan EAS, Canyon D, Younesc MWF, Wahab HA, Mansour AH. A review of botanical phytochemicals with mosquitocidal potential. Environment Intenational 31:1149-1166, 2005

15. Tavares ES, Julião LS, Lopes D, Bizzo HR, Lage CLS, Leitão SG. Analysis of the essential oil from leaves of three Lippia alba (Mill.) N. E. Br. (Verbenaceae) chemotypes cultivated on the same conditions. Revista Brasileira de Farmacognnosia 15:1-5, 2005.

16. Vitti AMS, Brito JO. Óleo essencial de eucalipto. (documentos florestais $n^{0} 17$ ). ESALQ Piracicaba, 2003.

17. World Health Organization. [on line] disponível em http://www.who.int/ mediacentre/factsheets/fs117/en/ [2008 novembro 18].2008.

18. World Health Organization. Dengue bulletin: Situation Dengue/Dengue hemorrhagic fever in SEA countries, 2004. 